\title{
Investigating The Effect of Organizational Amnesia on The Performance of Small And Medium-Sized Enterprises
}

\author{
Andi Muhammad Sadat \\ Jakarta State University, Indonesia \\ andims@unj.ac.id
}

Mei-Lan Lin

Southern Taiwan University of Science \& Technology, Taiwan

mllin@stust.edu.tw

\begin{abstract}
This research aims to investigate organizational amnesia as the failure of organizations to learn reliably at the organizational level, and it is hypothesized to influence the SMEs' performance. The authors examined indicators obtained from focus group discussion for representing organizational amnesia, then performed exploratory factor analysis based on a data survey of 200 participants from SMEs "Batik Trusmi" Cirebon in West Java to explore factors and retain firmed indicators. The empirical results found that all items representing organizational amnesia were formed into three factors: Undistributed Information, Employee Incompetence, and Knowledge Utilization. The first two factors are positively correlated to organizational performance, while the latter is negatively correlated. Those findings are expected to contribute significantly to the concept of organizational amnesia, particularly in SMEs. Conclusion and direction for future research are provided.
\end{abstract}

Keywords: Organizational Amnesia, Organizational Performance, Small and Medium-Sized Enterprises, Undistributed Information, Employee Incompetence, Knowledge Utilization

\section{INTRODUCTION}

Small and medium-sized enterprises (SMEs) with 200 or fewer employees become the most significant business sector in each country [1]. Governments worldwide are increasingly promoting and supporting SMEs' growth as part of their national development strategy. However, different from the large organizations with enough resources to support their performance, SMEs have some barriers, such as a low budget to maintain knowledge resources, and limited incentive makes members of organization reluctant to share their knowledge [2], so that the learning activities have difficulty to be utilized, and fundamentally will affect firm performance [3]. In Indonesia, the presence of SMEs has a prominent contribution. Since economic precarious in 1997 and word economic crisis in 2008, the SMEs absorbs more than 9.4 million employees and contributed 14,2 percent of total non-oil industry export. 
According to JICA (2006), if 5\% of SMEs' Indonesia can be empowered, they will be a powerful supporter for big industries and the national economy [4].

One of the SME clusters in West Java-Indonesia is "Batik Trusmi" Cirebon, which has employed hundreds of craftsmen. The existence of this cluster has been accelerating local business activities. Nevertheless, since decades ago, there are some indications that Batik Trusmi has not been experiencing growth significantly. One of the causes is the emergence of competitors from other regions and the inability of SMEs in Batik Trusmi to optimize their resources [5]. Batik has many designs and must adjust the market needs, requiring internal management to utilize knowledge and information appropriately. However, prior studies tend to analyze dissemination and highlight the adoption of knowledge management in large companies rather than the micro-sized organization. Only in recent years, the scholars have been concentrating attention on knowledge management in SMEs' context [6-9] so it is reasonable if the framework of knowledge management in SMEs is still fragmented [10].

Therefore, there are several motivations to accomplish this research: first, since still few pieces of research that undertake to examine the existence and the influence of organizational amnesia in the SMEs' context, so it would be beneficial to fill this gap, even though some scholars have introduced the term a couple of decades ago [11] however, the dimensions and indicators are still being developed to measure it [12]. Next, the authors chose to perform this study because there was still a paucity of research that made SMEs the object of research in Indonesia, so the appearance of this investigation will make a notable contribution for local companies and the regulator. Last, investigating organizational amnesia will support business actors to clearly understand that an organization is essential to utilize the knowledge generated from their learning process to create value and competitive advantage [13]. Based on the explanation above, this research address answer the questions: does organizational amnesia exist in SMEs? Furthermore, what is the effect of organizational amnesia on SMEs' performance?

\section{LITERATURE REVIEW AND HYPOTHESES}

\subsection{Organizational Amnesia}

Despite the tendency to develop organizational learning capability in SMEs context, the researches have shown that it is not easy for an organization to learn [14]. Not all companies can build learning capabilities, and most of them have a natural tendency to forget [15]. The phenomenon where an organization fails to benefit from its past experiences in knowledge management is called organizational amnesia [11]. Since the research regarding knowledge management was addressed more to the large enterprises [2], the authors will investigate the existence of organizational amnesia and how this phenomenon influences organizational performance in small and medium-sized enterprises. This kind of situation would influence the organizations to have a particular disposition, which will affect their overall decision and performance. Organizational amnesia indicates an enterprise has either lost its memory or is unable to recall the experience, so it will hamper him from learning from one part to another in the organization [14]. Then it will influence the organizational performance directly.

To recognize the causes of organizational amnesia, it essential to know the organization learning process [14]. Learning organization is action-oriented activities that are conducted to create and expand the capacity to learn [16]. Some scholars had made efforts to explain the elements of organizational learning process [17]. For 
example, [18] described four aspects of learning organization construct. The first is the storage of knowledge in organizational memory, in which the learning activity had been the implementation of knowledge at dissimilar stages. Second, the aspect of learning is in the term of vocational perspective which learning organization is viewed as a place for individuals to learn. The third is the learning environment perspective, which identifies an organization as a spot to facilitate the learning activities for members. The last is the learning formation perspective that views learning organization as a flexible aspect. Since knowledge is a non-figurative that includes all individual experiences, such as values, intuition, and expertise that provide a context and framework for incorporating new experiences and information, knowledge should appear in organizations' documents and daily activities.

Furthermore, the appearance of organizational amnesia will make it difficult for enterprises to construct organizational learning activities due to the nature of knowledge itself [14]. Also, SMEs tend not to put knowledge management as their priority. For example, only $24 \%$ of Icelandic micro-sized firms have a knowledge management program in place [19]. From these perspectives, it can be proposed that organizational amnesia can happen in all the stages of organizational learning process [20], and it also appears in SMEs' context.

\subsection{Organization Amnesia and SMEs' Performance}

Organizational amnesia indicates that organizations lose their memories, making them unable to recall past knowledge and inability to communicate within the organization [14]. In the context of SMEs with limited resources, it is often found that the absence of a member for a particular time will predispose the organization process directly. In other words, SMEs are consistently on the circumference of corporate amnesia [21]. It can also be said that SMEs are always living with amnesia, which knowledge management and organizational learning are good to have but very difficult to implement. Consequently, it will place the SMEs in difficulty creating product differentiation, improving innovation, and responding to market preferences. Common views state that to reciprocate the uncertainty of the business environment, the firms need to respond to their customers carefully, developing an excellent product while at the same time preparing the internal fit system in optimizing their knowledge. Otherwise, the traditional management of SMEs has never sufficient as a weapon for competition. Therefore, the participation of all the organization members in developing and maintaining the business process will be a fundamental factor for future organizational performance [22].

Even though scholars have a different definition and approach to SMEs, they also have similarities in transparency, knowledge capture, and the struggle to compete in the market that will affect their performance. In this paper, organizational performance is defined as the extent to which a company achieves its business objectives which can be measured by several factors, such as overall success, market share, growth rate, profitability, and innovation compared to its competitors [23], [24]. Since the framework of knowledge management in SMEs is still fragmented [10], [12], it is necessary to investigate the nature of amnesia in SMEs' context. As we know, even though the amnesia terminology had been appeared decades ago [11], several scholars come later with different names such as organizational forgetting [25], [26], and organization unlearning [27] to explain this phenomenon.

However, it is still a paucity of study exploring the nature of amnesia in the SMEs context. Furthermore, based on the explanation above, the authors proposed a 
single research hypothesis: "The presence of organizational amnesia is significantly related to the SMEs' performance."

\section{METHODOLOGY}

This study applied mixed methods by combining qualitative and quantitative approaches. Firstly, since the construct of organizational amnesia still needs more attention to be investigated, then the in-depth interview was selected as a beginning method to find some insights that will be used for guiding Focus Group Discussion (FGD). This interview was conducted on six respondents. Those participants were four business owners and two top managers who run their business in Batik Trusmi Cluster, West Java-Indonesia. Afterward, the FGD was arranged in two different groups, with eight respondents on each. The participants were the combination between business owners ( 6 persons), top managers ( 6 persons), boards of batik business association ( 2 persons), and government representatives ( 2 persons). The FGDs were held on two days, and each group was arranged by a neutral person and accompanied by business practitioners and academics.

Twenty-three indicators were developed from the FGD participant consensus to represent organizational amnesia. The final questionnaire consists of 28 main questions that include five questions for organizational performance adapted from [23]. A five-point Likert scale was used for all the items, starting from 1 for strongly disagree to 5 for strongly agree.

Secondly, before collecting data on the target respondent, the author conducted a pre-test to verify the entire items of the questionnaire in terms of readability and understanding. This pre-testing was conducted on six males and four females. They were asked to answer the whole items in the questionnaire by asking the intent of each item using the respondent's own language. The results show that the respondents can understand all indicators given and provide responses as expected.

Thirdly, the questionnaires were distributed in Batik Trusmi Cluster in Cirebon, West Java, Indonesia using a convenient sampling method. This approach is a type of non-random sampling where the elements of the target population are fit with practical criteria of the study, particularly be easily accessed by authors. Then 209 questionnaires were distributed from July to September 2018. However, as many as nine questionnaires cannot be used because most parts were blank. It was only 200 participants responses that can be processed in the next step.

\section{ANALYSIS AND RESULTS}

Data analysis in this research was applied in two steps. First, the authors conducted exploratory factor analysis (EFA) for organizational amnesia and organizational performance constructs to discover the number of indicators influencing variables and analyze which indicators nested together. A fundamental concept of EFA is to discover the number of common factors that have an explanation for the correlation [28], and this method is employed when the nature and characteristics of a construct are still unknown [29]. the EFA was performed by the Statistical Package for the Social Sciences (SPSS) 18 in which is often used in social and business science fields [30]. Next, perform the linear regression to see how the correlation was formed between some independent and dependent variables. This 
regression analysis will prove hypotheses and whether a model is fit to describe a phenomenon [31].

\subsection{Respondent profiles}

A total of 200 respondents were collected in this study. Most of them were males 131 (65\%), while female respondents are $69(35 \%)$. The majority of respondent's ages are between 41-60 age group (176 persons), and the rest are between 21-40 years old (17 persons) and above 60 years old ( 7 persons). Furthermore, most of the respondents are owners, which is 53\% (106 persons), while the rest of them consecutively $25 \%$ (50 persons) and 22\% (44 persons) are directors and managers. As many as $50 \%$ of the respondents have an industry that has been established less than 16 years. Meanwhile, the second and third places are established in two groups consecutively 16-30 and 31-45 years. Meanwhile, the second and third places are established in two groups consecutively 16-30 and 31-45 years. Only a few respondents were established for more than 45 years. Respondent's profile can be seen in Table 1 below.

Tabel 1. Respondent profile

\begin{tabular}{llcc}
\hline \multicolumn{2}{c}{ Characteristics of Sample } & frequency & Percent \\
\hline \multirow{4}{*}{ Sex } & Male & 131 & 65 \\
& Female & 69 & 35 \\
& Total & 200 & 100 \\
Ages & $21-40$ years & 17 & 8 \\
& $41-60$ years & 176 & 88 \\
& $>60$ years & 7 & 4 \\
\multirow{5}{*}{ Level } & Total & 200 & 100 \\
& Owner & 106 & 53 \\
& Director & 50 & 25 \\
& Manager & 44 & 22 \\
& Total & 200 & 100 \\
& $<16$ years & 100 & 50 \\
& $16-30$ years & 50 & 25 \\
& $31-45$ years & 45 & 22 \\
& $46-60$ years & 5 & 3 \\
& Total & 200 & 100 \\
\hline
\end{tabular}

\subsection{Results}

\subsubsection{Exploratory factor analysis}

The Exploratory Factor Analysis (EFA) was chosen because the author had no initial factors that want to be tested [32-34]. We can find out how the correlation formed between the indicators and how many new factors are formed by performing EFA. Based on the consensus obtained during the FGD, the authors establish some indicators that represent organizational amnesia (OA) while the items of organizational performance (OP) were taken from [23]. Furthermore, EFA will be applied in two main stages. First, it is performed on the 23 indicators of OA to know which items are valid, how the correlation among the indicators, and how many new factors are formed to represent the OA construct. Second, similar to the OA's EFA process, the five OP items were tested to get indicators that represent OP on SMEs in the Batik Trusmi cluster. 
The EFA processing on the 23 indicators of OA was performed up to four times. For the first time, seven new factors formed, and the KMO (Kaiser-Meyer-Olkin) value above 0.6. It means that EFA can be processed [35]. Nevertheless, some indicators have a loading factor below 0.55 , so that the author needs to reduce these indicators because they do not meet the requirements [36-38], [32], those indicators are OA6, OA8, OA10, OA20, OA21, and OA23. The second EFA was performed with a KMO value above 0.6 , and five new factors formed.

However, the five indicators still do not meet the requirements, so they must be reduced at the next step. The third stage analysis is performed by reducing the item number OA7, OA11, OA16, OA19, and OA22, and the results show that the KMO score is above 0.6 with three new factors formed. However, the rest of the 12 indicators grouped into three new factors still have one indicator with a loading factor below 0.55 (OA9). Hence, the authors have to perform the following process by reducing the indicator. Then the last EFA analysis on OA indicators provides a KMO score above 0.6 , and all the indicators have a loading factor above 0.5 . It means that the factor analysis can be accepted.

After conducting several stages of factor analysis on OA indicators, the next step is to perform factor analysis for OP indicators. The first-factor analysis is performed on five OP indicators, and the results show that the KMO score is more than 0.6 , so factor analysis can be performed. However, on the component matrix, it appears that one of the indicators (OP1) has a loading factor below 0.55, thus requiring the authors to reduce the indicator and perform the next step. The secondfactor analysis for OP indicators provides a KMO score above 0.6 , and no more indicator has a loading factor value below 0.55 , so the results can be accepted.

Furthermore, since OP indicators have only one factor formed, the naming process only focuses on OA indicators. The naming process of new factors can be performed by discussing with some assessors and referring to previous theories [32], [36]. In this process, the authors employed three assessors: two academics and one SME practitioner consecutively. We agreed that the labeling is based on two or three indicators with the highest loading factor in each group [39]. By looking at the indicators of OA that made up three new factors and we named them as Undistributed Information (OAa), Knowledge Utilization (OAb), Employee Incompetence (OAc). Table 2 shows the final result for EFA analysis. 
Table 2. EFA Results for all variables and indicators

\begin{tabular}{|c|c|c|}
\hline Factors and indicators & Sources & $\begin{array}{c}\text { Loading } \\
\text { scores }\end{array}$ \\
\hline Undistributed Information (OAa) & $\begin{array}{l}\text { Obtained } \\
\text { from FGD }\end{array}$ & $\alpha=0.908$ \\
\hline - always coordinate each other (OA1) & & .750 \\
\hline - learn from past experiences (OA2) & & .870 \\
\hline - communication among members is rare (OA3) & & .855 \\
\hline - sharing of information is not a priority (OA4) & & .872 \\
\hline - tend to look for a new solution for the same problem (OA5) & & .804 \\
\hline Knowledge Utilization (OAb) & & $\alpha=0.650$ \\
\hline - update information about organization activities (OA13) & & .751 \\
\hline - improve the previous strategy to increase sales (OA14) & & .678 \\
\hline Factors and indicators & Sources & $\begin{array}{c}\text { Loading } \\
\text { scores }\end{array}$ \\
\hline $\begin{array}{l}\text { - organization strategy is developed based on } \\
\text { information held (OA18) }\end{array}$ & & .624 \\
\hline Employee Incompetence (OAc) & & $\alpha=0.611$ \\
\hline - the learning ability of employees are slow (OA12) & & -.672 \\
\hline $\begin{array}{l}\text { - employees are sometimes absent for a certain period of } \\
\text { Time (OA15) }\end{array}$ & & .522 \\
\hline - takes a long time to train new employees (OA17) & & -.635 \\
\hline Organizational Performance (OP) & $\begin{array}{l}\text { Adapted } \\
\text { from } \\
\text { Deshpande et } \\
\text { al. (1993) }\end{array}$ & $\alpha=0.646$ \\
\hline - our businesses are less profitable (OP2) & & .628 \\
\hline - our businesses are larger (OP3) & & .737 \\
\hline - our businesses have a larger market share (OP4) & & .715 \\
\hline - our businesses are growing more slowly (OP5) & & .540 \\
\hline
\end{tabular}

\subsubsection{Linear regression}

Linear regression aims to determine the relationship between the independent and dependent variables and assess how well independent variables can predict dependent variables. Since the purpose of this study is to look at the effect of organizational amnesia on SMEs' performance. Then by employing the linear regression using SPSS 18 software, the authors input all the factor scores, namely: Undistributed Information (OAa), Knowledge Utilization (OAb), and Employee Incompetence (OAc), as the independent variables. The results of all three new factors correlate significantly with OP, which is P-value $<0.05$. Two of these factors have a Pearson correlation value with a negative sign: OAa and OAc. Meanwhile, factor $\mathrm{OAb}$ positively correlates with $\mathrm{OP}$ with each correlation coefficient consecutively OAa: -.234; OAb: .302; and OAc: -.406 (Table 3). 
Table 3. Pearson Correlations for All Factors

\begin{tabular}{llrrrr}
\hline & & OP & OAa & OAb & OAc \\
\hline \multirow{3}{*}{ Pearson } & OP & 1.000 & -.234 & .302 & -.406 \\
Correlation & OAa & -.234 & 1.000 & -.112 & .110 \\
& OAb & .302 & -.112 & 1.000 & .000 \\
& OAc & -.406 & .110 & .000 & 1.000 \\
\hline \multirow{3}{*}{ Sig. (1-tailed) } & OP &. & .000 & .000 & .000 \\
& OAa & .000 &. & .057 & .060 \\
& OAb & .000 & .057 &. & .500 \\
& OAc & .000 & .060 & .500 &. \\
$\mathrm{~N}$ & OP & 200 & 200 & 200 & 200 \\
& OAa & 200 & 200 & 200 & 200 \\
& OAb & 200 & 200 & 200 & 200 \\
& OAc & 200 & 200 & 200 & 200 \\
\hline
\end{tabular}

Based on the value of regression coefficients above, it can be seen that all the three factors, namely: OAa (Undistributed Information), OAb (Knowledge Utilization), and OAc (Employee Incompetence), are correlated significantly ( $\mathrm{p}<$ $0.05)$ with VIF and Tolerance scores state around 1,000, so they can predict the regression model. The equation is $\mathrm{Y}=.022+(-.141) \mathrm{OAa}+.284 \mathrm{OAb}+(-.388) \mathrm{OAc}$ (Table 4).

Table 4. Regression Coefficients of The Four Factors

\begin{tabular}{|c|c|c|c|c|c|c|}
\hline & \multirow[t]{2}{*}{ Model } & \multicolumn{2}{|c|}{$\begin{array}{l}\text { Unstandardized } \\
\text { Coefficients }\end{array}$} & \multirow{2}{*}{$\begin{array}{c}\text { Standardized } \\
\text { Coefficients }\end{array}$} & \multirow[t]{2}{*}{$\mathrm{t}$} & \multirow[t]{2}{*}{ Sig. } \\
\hline & & B & $\begin{array}{l}\text { Std. } \\
\text { Error }\end{array}$ & & & \\
\hline \multirow{4}{*}{1} & (Constant) & .022 & .061 & & .355 & .723 \\
\hline & $\mathrm{OAa}$ & -.141 & .054 & -.160 & -2.603 & .010 \\
\hline & $\mathrm{OAb}$ & .284 & .061 & .284 & 4.664 & .000 \\
\hline & OAc & -.388 & .061 & -.388 & -6.373 & .000 \\
\hline
\end{tabular}

Table 5 below explains how strong the correlation between independent variables and $\mathrm{OP}(\mathrm{R}=.530)$, which is the value of $\mathrm{R}$ between $0.5-0.6$, explains that the correlation formed between independent variables and OP is fair. While the value of $\mathrm{R}^{2}=0.281$ means that the dependent variable can only be explained by the independent variable of $28.1 \%$. In other words, the increase and decrease of the independent variable can predict the rise and fall of the OP.

Table 5. Model Summary ${ }^{\mathrm{b}}$

\begin{tabular}{ccccc}
\hline Model & $\mathrm{R}$ & $\mathrm{R}$ Square & $\begin{array}{c}\text { Adjusted R } \\
\text { Square }\end{array}$ & $\begin{array}{c}\text { Std. Error of the } \\
\text { Estimate }\end{array}$ \\
\hline 1 & $.530^{\mathrm{a}}$ & .281 & .270 & .85438 \\
\hline
\end{tabular}

a. Predictors: (Constant), OAc, OAb, Oaa

b. Dependent Variable: OP

Furthermore, table 6 below shows the ANOVA results that explain whether the established regression model fit and able to significantly explain the proportion of variance, which is p-value $<0.05$ explains the regression model that is formed significantly able to predict the OP outcome. 
Table 6. ANOVA ${ }^{\mathrm{a}}$

\begin{tabular}{rlrrrrr}
\hline Model & & $\begin{array}{r}\text { Sum of } \\
\text { Squares }\end{array}$ & Df & $\begin{array}{r}\text { Mean } \\
\text { Square }\end{array}$ & F & Sig. \\
\hline \multirow{2}{*}{1} & Regression & 55.925 & 3 & 18.642 & 25.538 & $.000^{\mathrm{b}}$ \\
& Residual & 143.075 & 196 & .730 & & \\
& Total & 199.000 & 199 & & & \\
\hline
\end{tabular}

a. Dependent Variable: OP

b. Predictors: (Constant), OAc, OAb, OAa

\subsubsection{Validity and Reliability Test}

Validity is the extent to which the accuracy of a measuring instrument in performing the measurement. In other words, it is able to obtain the exact data of the variables studied. The SPSS program can perform a validity test with Pearson Correlation value, which correlates each indicator with the total score of indicators.

- If $\mathrm{r}_{\text {count }}>$ rtable, then the indicators are declared valid.

- If $r_{\text {count }}<r_{\text {table }}$ or $r_{\text {count }}$ is negative, then the indicators are declared invalid.

The $r_{c o u n t}$ value can be seen on the Pearson Correlation results in Table 3 above, whereas $r_{\text {table }}$ value is obtained by $\mathrm{df}=\mathrm{n}-2$ or $200-2=198$ (with two side tests is 0.139). Based on the validity test for each factor, all indicators have Pearson correlation value more than $\mathrm{r}_{\text {table }}\left(\mathrm{r}_{\text {count }}>0.139\right)$. So, it can be concluded that all indicators that representing each factor are valid [40]. Otherwise, if all loading factors for the indicators are statistically significant, convergent validity will be met. Based on the factor analysis results above, the indicators loading of each factor exceeds the critical value of 0.55 as recommended by [41].

Next, a reliability test shows the extent to which the results of a measurement can be trusted. If it is conducted against the same group of people, it will relatively get a similar result. The reliability test is a measure of the stability and consistency of respondents in answering the questions. Reliability was tested by Cronbach's Alpha, and based on the value for all factors consecutively $\mathrm{OAa}=0.908, \mathrm{OAb}=0.650, \mathrm{OAc}$ $=0.611$ and $\mathrm{OP}=0.646$ (see table 2). So, it can be concluded that the measuring tools on the questionnaire have been reliable since, in exploratory research, the Cronbach's Alpha values of $0.60-0.70$ are acceptable [42], [43].

\section{DISCUSSION AND CONCLUSION}

Based on the survey conducted to analyze what factors cause organizational amnesia and its effect on SMEs' performance, the empirical results found that three kinds of amnesia factors influence the organization's performance. First, Undistributed Information, since the exodus of employees frequently occurs in SMEs, will directly impact the company performance because they will go along with their knowledge without ever being distributed to the organization entirely. As we knew that knowledge has two forms, namely explicit and tacit knowledge [45]. Explicit knowledge is often referred to as know-what that can be easier to distribute from one employee to another due to this kind of knowledge is formal such as rules, procedures, etc. While tacit knowledge is based on personal experiences and incorporated into the individual's memory, it is not easy to distribute because it requires physical interactions [47]. It means that the departure of experienced employees making the knowledge cannot be distributed, communicated, and shared with other parts of the organization. This kind of situation is also mentioned by [14] as the "space-based" 
problem. The organization cannot diffuse lessons learned and fails to share information from one point to another in the organization.

The next factor is Employee Incompetence. This problem will be leading to the knowledge being lost over time in an organization. The inability of the SMEs' employees as well as management to determine which information or knowledge to retrieve and store can affect the loss of that information and knowledge. Previous studies claim that the lack of personal motivation and competence among those who have undergone the learning causes the emergence of organization amnesia [14], [11], [46]. This situation makes an organization unable to perform the learning process and inhibits organizational learning [14]. Which is the real obstacle is the employees do not have enough competence due to some reasons, such as the lack of experience and education makes the information or knowledge may be lost during the transfer process.

As prior scholars [44] explained, the organizational failure to transfer the knowledge can occur during the integration and institutionalized process. It can involve the workers as individuals and larger groups such as departments and organizations. In other words, organization amnesia can occur in all four stages of organizational learning [20]. Therefore, the inability of the employees to transfer knowledge properly will put an organization to repeat the same process to find solutions for the same problems [14]. Then it can be proved that the inability of an organization, whether individual or institutional level, to learn will affect the organizational performance.

Furthermore, the last factor that affects organization performance is Knowledge Utilization. It is in line with previous studies that knowledge utilization positively correlates with organizational performance [3]. It means that since the organization can utilize its knowledge, obtain benefit from its experience, it will help the organization increase its performance. The author argued that the results of this study are quite interesting since the initial goal is to investigate and explore factors and retain firmed indicators that can represent organization amnesia.

Summarily, it can be concluded that Undistributed Information and Employee Incompetence is negatively correlated to Organisational Performance. In contrast, Knowledge Utilization is positively correlated to Organisational Performance. The higher the level of knowledge that is not transferred and the higher the incompetence of employees, the lower the organization's performance. Conversely, the higher the knowledge that can be utilized, the higher the performance of the organization.

\section{LIMITATION AND FUTURE RESEARCH}

Similar to other studies, this study also has limitations. First, the following research should consider the number of respondents collected because it will influence the coefficient correlation of each factor. Second, since the construct of organizational amnesia is still fragmented and mostly in conceptual manuscript [12], it would be precious if the author conducts the same study that applies the same indicators into distinct or similar SMEs, but it undertakes in a different time. Third, applying a new framework by employing potential variables such as organizational learning and knowledge management orientation as mediation or moderation in the relationship between organization amnesia and organization performance, or vice versa. That would be interesting to enrich the knowledge management literature, especially in the SMEs context. 


\section{REFERENCES}

[1] N. Culkin and D. Smith, "An emotional business : a guide to understanding the motivations of small business decision takers," Qual. Mark. Res. An Int. J., vol. 3, no. 3, pp. 145-157, 2006.

[2] S. J. Hall and C. De Raffaele, "Corporate amnesia in the micro business environment," Comput. Sci. Inf. Syst. (FedCSIS), 2013 Fed. Conf., pp. 12471251, 2013.

[3] T. H. Keh, T. T. M. Nguyen, and P. H. Ng, "The effects of entrepreneurial orientation and marketing information on the performance of SMEs," J. Bus. Ventur., vol. 22, pp. 592-611, 2007.

[4] I. Yamamoto-JICA, Learning Technologies on SMEs in Indonesia: A Case Study of Metal and Machinery, in the DR. Zulkieflimansyah, Ph.D, 2006.

[5] Merakati, Indah, Rusdarti Rusdarti, and Wahyono Wahyono. "Pengaruh orientasi pasar, inovasi, orientansi kewirausahaan melalui keunggulan bersaing terhadap kinerja pemasaran." Journal of Economic Education 6, no. 2, pp. 114-123, 2017.

[6] R. S. Frey, "Knowledge management, proposal development, and small businesses," J. Manag. Dev., vol. 20, no. 1, pp. 38-54, 2001.

[7] R. Mcadam and R. Reid, "SME and large organisation perceptions of knowledge management: comparisons and contrasts," J. Knowl. Manag., vol. 5, no. 3, pp. 231-241, 2001.

[8] K. Y. Wong and E. Aspinwall, "An empirical study of the important factors for knowledge-management adoption in the SME sector," J. Knowl. Manag., vol. 9, no. 3, pp. 64-82, 2005.

[9] R. K. Pillania, "Strategic issues in knowledge management in small and medium enterprises," Knowl. Manag. Res. Pract., vol. 6, pp. 334-338, 2008.

[10] R. Cerchione, E. Esposito, and R. Spadaro, "A literature review on knowledge management in SMEs," Knowl. Manag. Res. Pract., no. August 2015, pp. 169177, 2016.

[11] A. Kransdorff, "Corporate Amnesia: Keeping Know-How in the Company." Butterworth Heinemann, Oxford, p. xxv, 194; 25 cm., 1998.

[12] Nafei, Wageeh A. "The impact of organizational forgetting on knowledge management: evidence from pharmaceutical industry in Egypt." International Business Research 10, no. 11, pp. 193-205, 2017.

[13] Tiwana, Amrit. The knowledge management toolkit: practical techniques for building a knowledge management system. Prentice Hall PTR, 2000.

[14] R. Othman and N. Hashim, "Typologizing organizational amnesia," Learn. Organ., vol. 11, no. 2/3, pp. 273-284, 2004.

[15] J. Conklin, "Designing Organizational Memory: Preserving Intellectual Assets in a Knowledge Economy," CogNexus Institute, pp. 1-41, 2001.

[16] M. Easterby-smith, "Disciplines of organizational learning: Contributions and critiques," Hum. Relations, vol. 50, no. 9, pp. 1085-1113, 1997.

[17] N. Birdthistle, "Family smes in Ireland as learning organizations," Learn. Organ., vol. 15 , no. 5 , pp. $421-436,2008$. 
[18] A. Örtenblad, "A typology of the idea of Learning organization,” Manag. Learn., vol. 33, no. 2, pp. 213-230, 2002.

[19] I. R. Edvardsson, "Knowledge management in smes: The case of Icelandic firms," Knowl. Manag. Res. Pract., vol. 4, no. 4, pp. 275-282, 2006.

[20] N. Bahra, Competitive Knowledge Management. Springer, 2001.

[21] S. J. Hall and C. De Raffaele, "Corporate amnesia in the micro business environment," omputer Sci. Inf. Syst. (FedCSIS), 2013 Fed. Conf., pp. 12471251, 2013.

[22] R. Choueke and R. Armstrong, "The learning organisation in small and medium-sized enterprises," International Journal of Entrepreneurial Behavior \&Research, vol. 4, no. 2, pp. 129-140, 1998.

[23] R. Deshpandé, J. U. Farley, and F. E. Webster, "Corporate culture, customer and innovativeness orientation in japanese firms: a quadrad analysis," J. Mark., vol. 57, no. 1, pp. 23-37, 1993.

[24] S. A. W. Drew, "From knowledge to action: the impact of benchmarking on organizational performance," Long Range Plann., vol. 30, no. 3, pp. 427-441, 1997.

[25] P. M. Holan and N. Phillips, "Remembrance of Things Past? The dynamics of organizational forgetting," Management Science, vol. 50, no. 11, pp. 1603-1613, 2004.

[26] Holan et al., Managing Organizational Forgetting. MIT Sloan Management Review, 45(2), pp. 45-51, 2004.

[27] Tsang, Eric WK, and Shaker A. Zahra. "Organizational unlearning." Human Relations 61.10, pp. 1435-1462, 2008.

[28] McDonald, R. P. "Factor analysis and related methods. Hillsdaie.", 1985.

[29] Goldberg, Lewis R., and Wayne F. Velicer. "Principles of exploratory factor analysis." Differentiating normal and abnormal personality 2, pp. 209-337, 2006.

[30] Allen, Peter James, and Kellie Bennett. PASW statistics by SPSS: A practical guide: Version 18.0. Cengage Learning, 2010.

[31] Rencher, Alvin C., and William F. Christensen. "Chapter 10, Multivariate regression-Section 10.1, Introduction." Methods of Multivariate Analysis, Wiley Series in Probability and Statistics 709, pp. 19, 2012.

[32] Bartholomew, David J., Fiona Steele, Jane Galbraith, and Irini Moustaki. Analysis of multivariate social science data. Chapman and Hall/CRC, 2008.

[33] Child, D. The essentials of factor analysis. 3rd ed. New York, NY: Continuum International Publishing Group, 2006.

[34] Courtney, Matthew Gordon Ray, and Matthew Gordon. "Determining the number of factors to retain in EFA: Using the SPSS R-Menu v2. 0 to make more judicious estimations." Practical assessment, research \& evaluation 18, no. 8, pp.1-14, 2013

[35] Field, A. "Exploratory factor analysis." Discovering statistics using SPSS, pp. 619-680, 2005.

[36] Cattell, R. B. Factor analysis. New York: Harper, 1952.

[37] Fruchter, Benjamin. "Introduction to factor analysis." 1954. 
[38] Guadagnoli, Edward, and Wayne F. Velicer. "Relation of sample size to the stability of component patterns." Psychological bulletin 103, no. 2, pp. 265-275, 1988.

[39] Frydenberg, E., \& Lewis, R. Adolescent Coping Scale: Administrator's manual. ACER: Hawthorn, Australia, 1993.

[40] Alhusin, Syahri. "Aplikasi statistik praktis dengan SPSS. 10 for windows". Edisi Kedua, Yogyakarta: Graha Ilmu, pp. 335-346, 2003.

[41] Nunnally, Jum C., Ira H. Bernstein, and Jos MF ten Berge. Psychometric theory. Vol. 226. New York: McGraw-hill, 1967.

[42] Nunnally, Jum C., and Ira H. Bernstein. "Psychological theory." New York, NY: MacGraw-Hill, pp. 131-147, 1994.

[43] Hair Jr., J. F., Black, W. C., Babin, B. J., Anderson, R. E., \& Tatham, R. L. Multivariate data analysis. 6th ed. New Jersey: PrenticeHall, Inc, 2006.

[44] M. M. Crossan, H. W. Lane, and R. E. White, "An organizational learning framework: from intuition to institution," Acad. Manag. Rev., vol. 24, no. 3, pp. 522-537, 1999.

[45] A. M. Sadat and M.-L. Lin, "Organizational amnesia: the barrier of value creation and organizational performance in small and medium sized enterprise," J. Bus. Behav. Entrep., vol. 2, no. 1, pp. 1-8, 2018.

[46] R. F. Santos, M. Oliveira, and C. Curado, "The effects of the relational dimension of social capital on tacit and explicit knowledge sharing: A mixedmethods approach," VINE Journal of Information and Knowledge Management Systems, vol.51, no.1, pp. 1-26., 2021.

[47] R.-Y. Chen and C.-T. Fangtsou, "Iot-enabled knowledge sharing-based collaborative software maintenance design approach," "Int. J. Electron. Commer. Stud., vol. 6, no. 2, pp. 163-186, 2015. 
